DOI: $10.17976 / j p p s / 2020.04 .13$

\title{
МЕСТО РОССИИ В МИРЕ \\ В ВОСПРИЯТИИ РЯДОВЫХ ГРАЖДАН: ИДЕНТИФИКАЦИОННОЕ ИЗМЕРЕНИЕ
}

\author{
Т.В. Евгеньева, Н.В. Смулькина, И.А. Цымбал
}

ЕВГЕНЬЕВА Татьяна Васильевна, кандидат исторических наук, доцент, доцент кафедры социологии и психологии политики факультета политологии, МГУ им. М.В. Ломоносова; профессор департамента политологии и массовой коммуникации факультета социологии и политологии, Финансовый университет при правительстве Российской федерации, Москва, email: etv133@mail.ru; СМУЛЬКИНА Наталья Валентиновна, кандидат политических наук, старший преподаватель кафедры социологии и психологии политики факультета политологии, МГУ им. М.В. Ломоносова, Москва, email: smulkina@mail.ru; ЦЫМБАЛ Ирина Андреевна, аспирант кафедры социологии и психологии политики факультета политологии, МГУ им. М.В. Ломоносова, Москва, email: tsymbal2013@inbox.ru

Евгеньева Т.В., Смулькина Н.В., Цымбал И.А. Место России в мире в восприятии рядовых граждан: идентификационное измерение. - Полис. Политические исследования. 2020. № 4. C. 181-191. https:// doi.org/10.17976/jpps/2020.04.13

Исследование выполнено в рамках проекта РФФИ № 18-011-01138А “Образ страны в российском обществе: политико-психологический анализ”.

Статья поступила в редакцию: 04.03.2020. Принята к публикации: 04.05.2020

\begin{abstract}
Аннотация. Статья базируется на результатах исследования, реализуемого на кафедре социологии и психологии политики факультета политологии МГУ им. М.В. Ломоносова, по выявлению закономерностей формирования и образносимволической специфики представлений российских граждан о своей и других странах, их взаимодействии в общемировом пространстве. Изучая содержание и структурные особенности этих представлений, мы можем определить характер и степень кристаллизации национально-государственной идентичности. В основе исследования лежит комплексная аналитическая модель, предполагающая изучение трех аспектов восприятия места России в современном мире. Первый - представления о России, пространственные и темпоральные характеристики, служащие отражением самоидентификации респондента в качестве российского гражданина. Второй - система образов и символов, репрезентирующих представления респондентов о мировом пространстве, месте в нем государств и регионов, особенностях их взаимодействия и взаимовлияния. Третий - символическая репрезентация восприятия отдельных стран через их отношения с Россией. Методология эмпирического исследования базируется на сочетании количественных и качественных методов: формализованное интервью, проективные методики. Разработанная модель исследования позволила выявить не только взаимосвязь между пространственными и темпоральными аспектами процесса восприятия, но также их место в структуре идентичности личности. Национальногосударственная идентичность респондентов отражается в оценках своей и других стран, в качестве субъектного фактора определяет восприятие места России в мировом пространстве, формирует образы прошлого и будущего.
\end{abstract}

Ключевые слова: национально-государственная идентичность, политическое восприятие, образ страны, пространственные образы, темпоральные образы, образы “своих" и "чужих".

\section{ПОСТАНОВКА ПРОБЛЕМЫ}

Вопрос о месте России в системе международных отношений перестал быть прерогативой дискуссий специалистов-политологов: массовое сознание 
по-своему реагирует на трансформацию сложившегося образа мира, актуализируя старые и создавая новые стереотипы.

Отсутствие адекватного отражения происходящих в мире геополитических сдвигов в сознании как рядовых граждан, так и некоторых представителей элит, может вести не только к взаимному непониманию между россиянами и гражданами других стран, а вследствие этого к возможным конфликтам, но и к внутрироссийским идентификационным расколам, активно используемым отдельными политическими акторами. Дополнительную остроту проблеме придает тенденция к переосмыслению исторических обоснований сложившихся геополитических конструкций.

Образ России, представление о ее месте в системе отношений с другими странами формируют своеобразную систему координат, в которой находит свое отражение национально-государственная идентичность российских граждан. В условиях глобальных трансформаций XXI в. от четкости этой системы, содержания и символической репрезентации представлений зависят не только ответ на вопрос “кто мы?”, но и динамика политических настроений в обществе, устойчивость политической системы в целом.

В этом контексте цель исследования - выявление закономерностей формирования и образно-символической специфики представлений российских граждан о своей и других странах, их взаимодействии в общемировом пространстве. Изучая содержание и структурные особенности этих представлений, мы можем определить характер и степень кристаллизации национальногосударственной идентичности.

Теоретический аспект исследования связан с необходимостью более глубокого понимания значимости пространственно-географических и темпоральных факторов в формировании образов государств и их роли в процессе национально-государственной самоидентификации граждан. Прикладные аспекты проблемы связаны с национальной безопасностью и развитием международного сотрудничества.

\section{ТЕОРЕТИЧЕСКИЕ ОСНОВАНИЯ ИССЛЕДОВАНИЯ}

Проблемное поле исследования предполагает опору на совокупность политологических, социологических и политико-психологических подходов, среди которых следует выделить четыре основных блока.

Работы первого блока отражают особенности политико-психологического подхода к исследованию политических образов и представлений. На кафедре социологии и психологии политики факультета политологии МГУ им. М.В. Ломоносова была создана политико-психологическая модель исследования политического восприятия, где внимание уделялся как факторам, влияющим на восприятие стран, государств и отдельных политических акторов [Шестопал, Смулькина 2018], так и особенностям репрезентации сформированных представлений через совокупность образов и символов массового сознания [Евгеньева, Селезнева 2017].

Второй блок - это работы, посвященные теоретическим аспектам формирования и репрезентации национально-государственной идентичности в современном мире. В качестве наиболее значимых можно привести работы М. Кастельса [Castells 1997], С. Хантингтона [Хантингтон 2004], Д. Маккрона и Ф. Беххофера [MacCrone, Bechhofer 2015], М. Сидди [Siddy 2017], а также 
российских исследователей И.С. Семененко [Семененко 2016], О.В. Поповой [Попова 2016] и В.В. Титова [Титов 2012].

Вопрос о факторах, определяющих национально-государственную идентичность, разрабатывается в современных европейских политико-психологических исследованиях в Германии, Бельгии и ряде других стран [Herb, Kaplan 2017; Ditlmann, Ropf-Beck 2019; Agirdag, Phalet, Van Houtte 2016].

Третий блок составляют работы авторов, анализирующих место пространственно-географических и исторических представлений в современной политике. Первоочередной интерес представляют работы, посвященные внешнеполитическим аспектам образов государств [Киселёв, Смирнова 2016], пространственному измерению образа страны [Замятин 2004; Окунев 2020], исторической памяти и исторической политике [The Politics of Memory in Postwar Europe 2006; Малинова 2018; Евгеньева, Титов 2017].

Четвертый блок включает в себя научные труды отечественных социологов, где внимание сфокусировано на рассмотрении представлений россиян о международной роли России и других стран. Особенности рационализированного внешнеполитического восприятия, изучение образов “страны-врага" и “страны-друга" наиболее детально изучались в 2008-2010 гг. и 2015-2016 гг. [Задорин 2008; Петухов 2010; Горшков, Петухов 2016; Митрофанова 2016]. В политической социологии предмет исследования в последние годы расширяется на уровень взаимного внешнеполитического восприятия [Снежкова и др. 2019].

\section{ТЕОРЕТИЧЕСКАЯ КОНЦЕПЦИЯ И МОДЕЛЬ ИССЛЕДОВАНИЯ}

Идентификационное измерение исследования особенностей восприятия России и ее места в современном мире опирается на политико-психологический подход к пониманию национально-государственной идентичности в качестве идентичности макрополитического типа, определяемой как “исторически и культурно обусловленная психологическая самоассоциация личности с геополитическим образом (образами) определенной национальногосударственной общности, имеющая в своем основании личностные мотивы и социальные ценности, закрепляющаяся и проявляющаяся через символические репрезентации" [Титов 2012]. Эта идентичность, как один из элементов структуры личности, является результатом ее самоидентификации в процессе поисков ответа на вопросы “кто я?” и “кто мы?”.

Ключевое место в этой системе координат занимают культурные, пространственные и исторические образы и символы, создающие ориентиры социальной и политической реальности [Евгеньева, Селезнева 2017].

Особенностью политико-психологического подхода к исследованию восприятия стран мира является обращение не только к рациональным, но и неосознаваемым аспектам этого процесса. В основе формируемого образа лежат часто не столько объективные знания о стране, сколько эмоционально окрашенные символы и стереотипы, полученные в результате случайного соприкосновения с фактами и событиями или конструирования их через каналы массовой коммуникации.

Е.Б. Шестопал обращает внимание на наличие субъектных факторов политического восприятия, отражающих часто не осознаваемые особенности социального и политического опыта личности. При анализе процесса воспри- 
ятия интерес представляет также выявление роли коммуникативного фактора, формирующего в массовом сознании совокупность символов и стереотипов, оказывающих влияние на репрезентацию представлений [Психология политического восприятия... 2012].

Авторы выдвигают гипотезу о ведущей роли в восприятии России, окружающего мира, регионов и отдельных стран такого субъектного фактора как национально-государственная идентичность личности. Базовыми элементами данного процесса выступают пространственные и темпоральные элементы формирующихся образов.

В основе исследования лежит комплексная аналитическая модель, предполагающая изучение трех аспектов восприятия места России в современном мире. Первый - представления о России, пространственные и темпоральные характеристики, служащие отражением самоидентификации респондента в качестве российского гражданина. Второй - система образов и символов, репрезентирующих представления респондентов о мировом пространстве и месте в нем России. Третий - восприятие отдельных стран через их отношения с Россией.

Методология эмпирического исследования базируется на сочетании количественных и качественных политико-психологических методов. Формализованное интервью предполагает выявление специфики представлений россиян о своей стране и окружающем мировом пространстве, об отдельных странах и регионах в контексте особенностей национально-государственной самоидентификации российских граждан (объем выборочной совокупности 1600 респондентов из 14 субъектов РФ). Проективные методики направлены на выявление глубинных оснований образов (количество рисунков 1 300).

Данная методология позволяет оценить неосознаваемую составляющую восприятия, реконструировать многомерную пространственно-темпоральную модель места России в современном мире, выявить ее идентификационную составляющую у представителей различных поколений российских граждан.

\section{АНАЛИЗ РЕЗУЛЬТАТОВ ИССЛЕДОВАНИЯ}

\section{Восприятие России: образы пространства}

Пространственный аспект образа России занимает одно из центральных мест в массовом сознании. Образ “своей” земли связан с особенностями процесса национально-государственной самоидентификации граждан.

С одной стороны, земля воспринимается не как самостоятельный объект, a, скорее, как производящая субстанция, кладовая ресурсов. Ресурсы как достоинство страны отмечали 61,5\% респондентов. Не менее значимой особенностью российской земли является способность порождать людей с особыми качествами (72\% респондентов).

С другой стороны, российская земля воспринимается как суровый край, неосвоенная территория, таящая в себе потенциальные опасности. Латентный, не вполне осознанный страх в отношении собственных территорий подкрепляется символической пустотой образа пространства России. Например, на рисунках жителей столицы Сибирь предстает незаполненным полем (в лучшем случае с изображением елей).

Неудивительно, что, отвечая на вопрос о возможных изменениях территории России в ближайшие 20 лет, часть респондентов легко изменяла 
государственные границы. Лишь 66,9\% опрошенных отметили, что границы России должны остаться неизменными. Заметны тенденции к сужению пространства в представлениях молодежи и его расширению у респондентов средней и старшей возрастных групп. Следует отметить, что феномен "сужения пространства" не проявлял себя до середины 2010-х годов.

Часть респондентов (26,9\%) преимущественно средней и старшей возрастных групп, не имея четких представлений о пределах собственной страны, склонялись к экспансионистским ориентациям. Присоединение Аляски - самый упоминаемый пример. Вопрос об изменении границ поднимался преимущественно в контексте обсуждения будущего страны жителями центральных регионов России, для которых образ границы не является персонализированным (граница лично от меня далеко). Для респондентов из периферийных регионов характерно более четкое "пограничное” восприятие.

Тенденция к расширению пространства проявила себя в условиях склонности некоторых опрошенных обращаться не к государственным, а к символическим границам страны. Характеризуя пределы России, 16\% респондентов ответили, что “Россия вообще не имеет границ". Некоторые говорили, что "Россия представлена во всем мире, она там, где звучит русская речь, где есть российская культура и нравы”. Стремление сделать другое (как правило, близлежащее) пространство потенциально своим, может быть объяснено скрытыми тревогами массового сознания, неосознаваемым стремлением обезопасить себя, очертив безопасное пространство.

В более глубоком исследовании нуждается выявленная тенденция рационализации сужения пространства в представлениях некоторых молодых россиян (до 24 лет). Они с уверенностью говорят о необходимости отказаться от части “нерентабельных территорий” (Курилы, Сахалин, отдельные регионы Кавказа и Крым). Указанная тенденция подобного политического восприятия также опирается на стереотип “большой неосвоенной земли”, но трансформируется в иной формат восприятия своей страны, нежели у представителей других поколений. У респондентов старших поколений образ “России сурового края” накладывается на порой противоречащий ему образ “богатой ресурсами земли”, формируя чувство избранности, исключительности российского народа. Для части респондентов молодого поколения (около 14\%) большие территории и неразработанные залежи природных ресурсов, наоборот, выступают в качестве символов потенциальных сложностей, вызовов для страны. Молодые респонденты не просто озвучивают дилемму “Почему чем меньше страна, тем лучше живет?”, но и предлагают сократить территории, чтобы избавиться от проблем.

Полученные данные об отсутствии четких представлений о границах у одной части респондентов и легком отношении к их изменению у другой подтверждают своевременность предлагаемых поправок в Конституцию РФ, закрепляющих незыблемость границ России.

\section{Восприятие России: темпоральные образы}

Образ территории страны и образы личного и государственного прошлого тесно взаимосвязаны (“здесь мои корни”, “эту землю наши предки защищали”). В меньшей степени заметна в ответах респондентов связь образа земли с образом будущего. Вероятно, это связано с несформированным в массовом 
сознании образом будущего. Результаты показывают, что современный россиянин зачастую не видит себя субъектом, участником будущего своей страны, испытывает страх в его отношении, неосознанно снимая с себя ответственность за него (см. рис. 1А). При этом коммуникативный фактор способствует формированию в массовом сознании ощущения “точки перелома”, формирует представления о необходимости изменить что-то “здесь и сейчас", чтобы предотвратить возможную катастрофу. Страх будущего также выступал одним из психологических оснований для формирования ориентации респондента на изоляционистский тип поведения страны в международных отношениях.

Образ прошлого России в массовом сознании более четок, однако, в свою очередь, фрагментирован, сверхчувствителен к дискурсу. Оценки прошлого страны опираются на восприятие времени как нелинейного состояния с контрольными точками в виде отдельных, не связанных между собою событий, а современной российской истории как “бесконечно длящегося настоящего”. Отсутствие представления о развитии чаще всего характерно для респондентов, прошедших политическую социализацию в последние 20 лет.

\section{Россия и мир: особенности политического восприятия}

Результаты исследования позволяют утверждать, что восприятие России, включенной в современные мировые процессы, достаточно амбивалентно и не вполне конгруэнтно на рациональном и неосознаваемом уровнях.

Проективные тесты выявляют у большинства опрошенных россиецентричный образ мира, где часть пространства выступает потенциально “своим”, а другая его часть “чужим”, в сочетании с матрешечным иерархичным принципом конструирования пространства, где присутствуют разноранговые центры силы и влияния.

Рисунок 1 (Figure 1)

Образ России: (А) “Затонет ли?” (женщина, 26 лет, Москва);

(Б) “От России как от прожектора идет свет...” (мужчина, 19 лет, Москва)

Image of Russia: (A) "Will it sink?” (woman, 26 years old, Moscow);

(B) "Russia Lights Like a Spotlight” (man, 19 years old, Moscow)

A

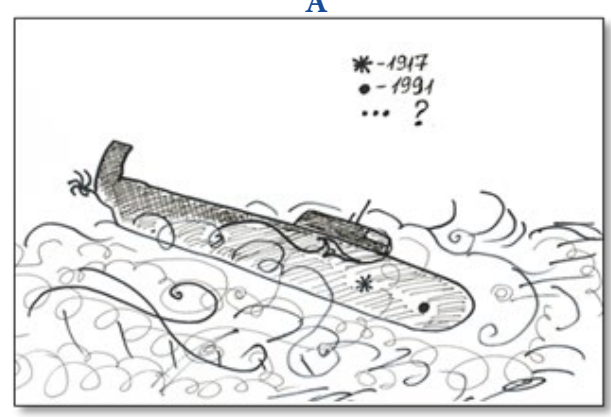

b

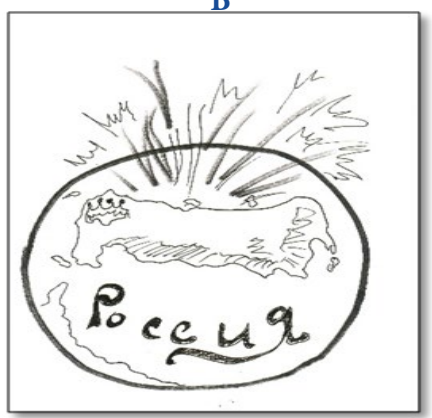

Место России в мире воспринимается респондентами, прежде всего, с учетом ее ресурсного потенциала. Внимание сфокусировано на ресурсноэкономических, культурных (часто также в виде ресурса), политико-идеологических и пространственно-географических образах (природные ископаемые, трудовые ресурсы, уровень развития экономики, богатство культуры и языка, 
привлекательность образа жизни, демократичность и традиционализм в мировоззрении) (см. рис. 1Б).

Данный аспект восприятия страны иллюстрируется множеством приведенных примеров из российской истории.

В структуре образа будущего России в контексте ожиданий и надежд внимание привлекает, прежде всего, оценка геополитического места нашей страны в мире и ожидаемая роль страны на мировой арене.

В ответах респондентов в равной степени присутствуют объективно противоположные мнения о предпочтительной позиции России в мировой политике. Одна часть респондентов акцентировала внимание на том, что они хотят видеть Россию сверхдержавой, не ввязывающейся в международные конфликты, но при этом распространяющей свою культуру и ценности по всему миру, объединяя вокруг себя страны постсоветского пространства, восприятие которых во многом связано со стереотипом “ненастоящего зарубежья”. Оценивая характер взаимоотношений России с другими странами, респонденты неосознанно обращались к символике справедливости и активного противодействия злу.

В ответах другой части респондентов присутствует альтернативное мнение, опирающееся на стремление видеть свою страну равноправным партнером в международных отношениях, субъектом, принимающим международные нормы и не стремящимся диктовать свои собственные правила. В данном случае акцент смещается к стереотипу “процветающей России”, ассоциирующемуся со стабильностью.

Можно сделать вывод, что темпоральные и пространственные представления достаточно фрагментарны и часто противоречат друг другу. Эта внутренняя противоречивость свидетельствует о структурной слабости, а размытость образов - о содержательной неопределенности национально-государственной идентичности респондентов.

\section{Восприятие зарубежных стран}

Идентификационное измерение восприятия зарубежных стран опирается на место образа “другого” в структуре национально-государственной идентичности личности. Проведенный анализ позволяет сделать вывод о содержательной и символической бедности образов стран при наличии тенденции к их субъективной поляризации. В сознании респондентов присутствуют две большие группы, условно определяемые как “свои” (“друзья” и “партнеры”) и “чужие" (“враги" и “конкуренты"). Если одна и та же страна может быть отнесена разными респондентами к различным группам: враг/конкурент (США), друг/партнер (Индия), то общая тенденция (категоризация в качестве "своих" или "чужих") в целом сохраняется. Исключением можно назвать Украину, образ которой в последние годы переместился из категории “своих" (братский народ) в категорию “чужих".

При описании “стран-друзей” (Беларусь, Армения, Казахстан, Индия, Бразилия) их жителям приписываются исключительно позитивные символические характеристики: доброта, дружелюбие, гостеприимство. Государство также оценивается позитивно как во внутриполитическом измерении (стабильное и успешно развивающееся), так и с точки зрения места в системе международных отношений. В восприятии большинства “стран-друзей" 
главную роль для респондентов играют историко-культурные, частично историко-политические аспекты сложившегося образа. Это характерно особенно для представителей старших поколений, в коллективной памяти которых сохранились символы “братства" народов.

При оценке стран в качестве “партнеров” (Индия, Китай, Казахстан, Беларусь, Испания, Франция) в качестве обоснования на первый план выходит та сторона образа, которая отражает представление о наличии совместных экономических и культурных проектов различного уровня. Эти представления формируются за счет коммуникативного фактора, в связи с этим сильно стереотипизированы и имеют ситуативный характер. В отличие от “друзей” “партнеры” могут вызывать у респондентов недоверие (непредсказуемый, хитрый). Так, например, Китай, несмотря на в целом позитивную оценку развития экономических отношений, в эмоциональном плане ассоциируется с не до конца осознаваемой опасностью (слишком непохожие язык, культура, традиции).

Образ “чужой” страны проявляется также на двух уровнях: “враг”, “конкурент". "Врагами” респонденты чаще всего называют Эстонию, Великобританию, Украину и США, “конкурентами" - США, Германию, Великобританию, Китай. Интересно, что при превращении Украины из “друга" во “врага" у части респондентов образуется внутренне противоречивый образ, в котором “врагом” становится государство Украина, а украинский народ продолжает восприниматься в качестве “своих" (славяне, братья). Здесь следует отметить роль коммуникативного фактора восприятия этой страны, который вступает в противоречие с формирующимися в течение длительного времени историко-культурными символами и стереотипами, чем определяется двойственность образа.

Коммуникативный фактор играет значимую роль в формировании образов как “врагов”, так и “конкурентов”. Обосновывая свой выбор, респонденты, как правило, не опираются на знание фактов, а воспроизводят коммуникативные стереотипы, приписывая странам характеристики, символически идентифицирующие “чужого”.

Основанием для оценки страны в качестве "врага” является образ исходящей от него опасности, “конкурента” отличает наличие ресурсного потенциала, с которым респонденты связывают тревожные ожидания.

Итак, центральным фактором в оценке той или иной страны для респондентов является ее восприятие в качестве “другого" в контексте отношений с Россией. В связи с этим значительная часть зарубежных стран остается в категории нейтральных, образ которых складывается из случайного набора символов, а иногда формирует представление "неведомого пространства" (например, страны Африки).

\section{ВЫВОДЫ}

Разработанная модель исследования восприятия стран мира и мирового пространства в идентификационном измерении позволила выявить не только взаимосвязь между пространственными и темпоральными аспектами процесса восприятия, но также их место в структуре идентичности личности.

Национально-государственная идентичность респондентов отражается в оценках своей и других стран, в качестве субъектного фактора определяет 
восприятие места России в мировом пространстве, формирует образы прошлого и будущего. В этом контексте можно говорить о россиецентричности образа мирового пространства, в котором образы стран и регионов воспринимаются, в первую очередь, в качестве символических “других", а их место в системе международных отношений оценивается в зависимости от степени близости (реальной или выдуманной респондентом) с Россией.

В то же время размытость и фрагментарность пространственных и темпоральных элементов образа России свидетельствуют о структурной слабости и содержательной неопределенности национально-государственной идентичности респондентов. Одним из проявлений данной закономерности стала когнитивная и символическая бедность образа пространства своей страны у представителей молодого поколения, непосредственно связанная с не до конца сформированной идентичностью. Это создает у части респондентов представление об “избыточности” российской территории, являющейся, по их мнению, лишь источником дополнительных проблем.

Данное обстоятельство может стать препятствием для полноценной самоидентификации молодежи в качестве граждан России - не случайно внимание общества было привлечено к обсуждению предложения о внесении в Конституцию РФ принципа незыблемости границ России.

Существенное влияние коммуникативного фактора на выявленные в процессе исследования проблемы указывает на необходимость целенаправленной информационной политики, направленной на формирование (в первую очередь, у молодежи) адекватного, содержательно и символически полного образа своей страны и ее места в мировом пространстве.

DOI: $10.17976 / j p p s / 2020.04 .13$

\title{
RUSSIA'S PLACE IN THE WORLD IN THE PERCEPTION OF NATIONAL CITIZENS: IDENTIFICATION DIMENSION
}

\author{
T.V. Evgenyeva ${ }^{1}$, N.V. Smulkina ${ }^{1}$, I.A. Tsymbal ${ }^{1}$ \\ ${ }^{1}$ Lomonosov Moscow State University. Moscow, Russia
}

EVGENYEVA, Tatiana Vasilievna, Cand. Sci. (Hist.), Associate Professor, Associate Professor of Department of Political Sociology and Psychology, Faculty of Political Science, Lomonosov Moscow State University; Professor, Political Science and Communication Program, Sociology and Political Science Department, Financial University under the Government of the Russian Federation, email: etv133@mail.ru; SMULKINA, Natalia Valentinovna, Cand. Sci. (Pol. Sci.), Senior Lecturer, Department of Political Sociology and Psychology, Faculty of Political Science, Lomonosov Moscow State University, email: smulkina@mail.ru; TSYMBAL, Irina Andreevna, Postgraduate Student, Department of Political Sociology and Psychology, Faculty of Political Science, Lomonosov Moscow State University, email: tsymbal2013@inbox.ru

Evgenyeva T.V., Smulkina N.V., Tsymbal I.A. Russia's Place in the World in the Perception of National Citizens: Identification Dimension. - Polis. Political Studies. 2020. No. 4. P. 181-191. (In Russ.) https://doi.org/10.17976/ jpps/2020.04.13

Acknowledgements. The study was supported by the Russian Foundation for Basic Research, project No. 18-011-01138A "The Image of the Country in Russian Society: A Political and Psychological Analysis".

Received: 04.03.2020. Accepted: 04.05.2020

Abstract. The article is based on the results of a study into Russian citizens' perception of Russia and other countries, conducted by the Department of Political Sociology and Psychology, Faculty of Political Science, Lomonosov Moscow State University. The purpose of the study is to identify if patterns form regarding figurative and symbolic idiosyncrasies into how Russian citizens perceive both their country and others, and such countries' interaction in the global sphere. Studying the content and structural features 
of these ideas, we can determine the nature and degree of how crystallized these ideas have become in national-state identity. The study is based on a comprehensive analytical model involving the study of three aspects of the perception of Russia's place in the modern world. The first is the idea of Russia: the spatial and temporal characteristics that serve as a reflection of the respondents' self-identification as a Russian citizen. The second is a system of images and symbols representing the respondents' ideas about the global sphere, the role of states and regions in it, and the features of their interaction and mutual influence. The third is a symbolic representation of how individual countries can be perceived through their relations with Russia. The empirical research methodology is based on a combination of quantitative and qualitative methods: formalized interviews, projective techniques. The research model developed revealed not only the relationship between the spatial and temporal aspects of the perception process, but also their place in the structure of personality identity. Respondents' national-state identification is reflected in the assessments of their country next to others, determines the perception of Russia's place in the world as a subjective factor, and forms the image of the past and future.

Keywords: national state identity, political perception, image of the country, spatial images, temporal images, images of "friends" and "strangers".

\section{References}

Agirdag O, Phalet K, Van Houtte V. 2016. European Identity as a Unifying Category: National vs. European Identification among Native and Immigrant Pupils. - European Union Politics. Vol. 17. No. 2. P. 285-302. https://doi.org/10.1177/1465116515612216

Castells M. 1997. The Power of Identity. Cambridge: John Wiley \& Sons. 585 p.

Ditlmann R., Ropf-Beck J. 2019. The Meaning of Being German: An Inductive Approach to National Identity. - Journal of Social and Political Psychology. Vol. 7. No. 1. P. 423-447. https://doi.org/10.5964/jspp. v7i1.557

Herb G., Kaplan D. 2017. Scaling Identities Nationalism and Territoriality. Lanham, Maryland: Rowman \& Littlefield. 226 p.

MacCrone D. Bechhofer F. 2015. Understanding National Identity. Cambridge: Cambridge University Press. $226 \mathrm{p}$.

Siddy M. 2017. National Identities and Foreign Policy in the European Union the Russia Policy of Germany, Poland and Finland. ECPR Press. 224 p.

The Politics of Memory in Postwar Europe. 2006. Ed. by R. Lebow, W. Kansteiner, C. Fogu. Durham: Duke University Press. 384 p.

Evgenyeva T.V., Selezneva A.V. 2017. Transformation of National-State Identity of Russian Youth in the Post-Soviet Period: Values' Foundations and Symbolic Representations. - Politeia. No. 4. P. 48-64. (In Russ.)

Evgenyeva T.V., Titov V.V. 2017. Images of the Past in the Russian Mass Political Consciousness: Mythological Dimension. - Political Science (RU). No. 1. P. 120-138. (In Russ.)

Gorshkov M.K., Petukhov V.V. 2016. Vneshnepoliticheskie orientatsii rossiyan v kontekste vyzovov sovremennoi global'noi politiki [Foreign Policy Orientations of Russians in the Context of the Challenges of Modern Global Politics]. - Politicheskaya nauka pered vyzovami global'nogo i regional'nogo razvitiya: nauchnoe izdanie [Political Science Facing the Challenges of Global and Regional Development: A Scientific Publication]. Ed. by O.V. Gaman-Golutvina. Moscow: Aspect Press. P. 606-634. (In Russ.)

Huntington S. 2005. Who are we? Challenges of American National Identity. (Russ. ed.: Huntington S. Kto my? Vyzovy amerikanskoi natsional'noi identichnosti. Moscow: AST Press. 635 p.)

Kiseliov I.Yu., Smirnova A.G. 2016. The Population's Perception of Foreign Policy Results - the Peculiarities. Vestnik instituta sotziologii. Vol. 7. No. 4. P. 136-154. (In Russ.) https://doi.org/10.19181/vis.2016.19.4.432

Malinova O.Yu. 2018. The Commemoration in Russia of the Centenary of the 1917 Revolution(s): Analysis of Strategies of the Key Mnemonic Actors. - Polis. Political Studies. No. 1. P. 9-25. (In Russ.) https://doi. org/10.17976/jpps/2018.01.02

Mitrofanova S.Yu. 2016. The Image of "Enemy Country" and "Friend Country" in the Ideas of Modern Students of a Technical University. - Economics and Sociology. No. 2. P. 19-23. (In Russ.)

Okunev I.Yu. 2020. Osnovy prostranstvennogo analiza: monografiya [Spatial Analysis Basics: Monograph]. Moscow: Aspect Press. 255 p. (In Russ.)

Petukhov V.V. 2010. Foreign Policy Priorities of the Mass Consciousness of Russians. - Sociological Studies. No. 11. P. 4-13. (In Russ.)

Popova O.V. 2016. Bazovaya matritsa gosudarstvennoi politiki identichnosti v sovremennoi Rossii [The Basic Matrix of State Identity Policy in Modern Russia]. - Politicheskoe prostranstvo i sotsial'noe vremya [Political Space and Social Time]. P. 160-165. (In Russ.) 
Psikhologiya politicheskogo vospriyatiya v sovremennoi Rossii [Psychology of Political Perception in Modern Russia]. Ed. by E.B. Shestopal. 2012. Moscow: ROSSPEN. 432 p. (In Russ.)

Semenenko I.S. 2016. Identity Politics and Identities in Politics: Interethnic Perspectives in a European Context. - Polis. Political Studies. No. 4. P. 8-28. (In Russ.) https://doi.org/10.17976/jpps/2016.04.03

Shestopal Ye.B., Smulkina N.V. 2018. Factors of Political Perception of Post-Soviet Countries in Contemporary Russian Society. - Polis. Political Studies. No. 1. P. 26-44. (In Russ.) https://doi.org/10.17976/ jpps/2018.01.03

Snezhkova I.A., Kalacheva I.I., Shalygina N.V., Gromov D.V. 2019. The Images of Russia and Belarus in the Views of the Youth of the Two Countries. - Vlast'. No. 1. P. 107-112. (In Russ.) https://doi.org/10.31171/ vlast.v27i1.6236

Titov V.V. 2012. Natsional'no-gosudarstvennaya identichnost' rossiiskoi molodezhi v nachale XXI veka [National-State Identity of Russian Youth at the Beginning of the 21st Century]. Moscow: Max Press. 168 p. (In Russ.)

Zadorin I.V. 2008. Integrational Orientations of the Population of the Cis Countries: Dynamics and Prospects. - Integration in Eurasia: A Sociological Dimension. Vol. 2. Moscow: INES. P. 61-89. (In Russ.)

Zamyatin D.N. 2004. Vlast' prostranstva i prostranstvo vlasti: Geograficheskie obrazy v politike $i$ mezhdunarodnykh otnosheniyakh [The Power of Space and the Space of Power: Geographical Images in Politics and International Relations]. Moscow: ROSSPEN. 349 p. (In Russ.)

\section{Литература на русском языке}

Горшков М.К., Петухов В.В. 2016. Внешнеполитические ориентации россиян в контексте вызовов современной глобальной политики. - Политическая наука перед вызовами глобального и регионального развития: научное издание. Под ред. О.В. Гаман-Голутвиной. М.: Аспект Пресс. С. 606-634.

Евгеньева Т.В., Селезнева А.В. 2017. Трансформация национально-государственной идентичности российской молодежи в постсоветский период: ценностные основания и символические репрезентации. - Полития: Анализ. Хроника. Прогноз. № 4. С. 48-64.

Евгеньева Т.В., Титов В.В. 2017. Образы прошлого в российском массовом политическом сознании: Мифологическое измерение. - Политическая наука. № 1. С. 120-138.

Задорин И.В. 2008. Интеграционные ориентации населения стран СНГ: динамика и перспективы. - Интеграция в Евразии: социологическое измерение. Вып. 2. М.: ИНЭС. С. 61-89.

Замятин Д.Н. 2004. Власть пространства и пространство власти: Географические образы в политике и международных отношениях. М.: РОССПЭН. 349 с.

Киселёв И.Ю., Смирнова А.Г. 2016. Особенности восприятия населением результатов внешней политики. - Вестник Института социологии. № 19. С. 136-154. https://doi.org/10.19181/vis.2016.19.4.432

Малинова О.Ю. 2018. Коммеморация столетия революции(й) 1917 года в РФ: анализ стратегий ключевых мнемонических акторов. - Полис. Политические исследования. № 1. C. 9-25. https://doi. org/10.17976/jpps/2018.01.02

Митрофанова С.Ю. 2016. Образ “страны-врага” и “страны-друга” в представлениях современных студентов технического вуза. - Экономика и социология. № 2. С. 19-23.

Окунев И.Ю. 2020. Основы пространственного анализа: монография. М.: Аспект Пресс. 255 с.

Петухов В.В. 2010. Внешнеполитические приоритеты массового сознания россиян Социологические исследования. № 11. С. 4-13.

Попова О.В. 2016. Базовая матрица государственной политики идентичности в современной России. - Политическое пространство и социальное время. С. 160-165.

Семененко И.С. 2016. Политика идентичности и идентичность в политике: этнонациональные ракурсы, европейский контекст. - Полис. Политические исследования. № 4. С. 8-28. https://doi. org/10.17976/jpps/2016.04.03

Снежкова И.А., Калачева И.И., Шалыгина Н.В., Громов Д.В. 2019. Образы России и Белоруссии в представлениях молодежи двух стран. - Власть. № 1. С. 107-112.

Титов В.В. 2012. Национально-государственная идентичность российской молодежи в начале ХХI века. М.: МАКСПресс. 168 с.

Хантингтон С. 2004. Кто мы? Вызовы американской национальной идентичности. М.: ООО АСТ. $635 \mathrm{c}$.

Психология политического восприятия в современной России. Под ред. Е.Б. Шестопал. 2012. М.: РОССПЭН. 432 с.

Шестопал Е.Б., Смулькина Н.В. 2018. Факторы восприятия постсоветских стран в современном обществе. - Полис. Политические исследования. № 1. С. 26-44. https://doi.org/10.17976/jpps/2018.01.03 